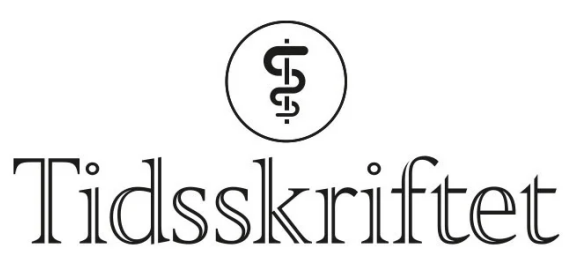

DEN NORSKE LEGEFORENING

\title{
Psykiatriens forventningskrise
}

KRONIKK

\section{ANDERS MALKOMSEN}

anders.malkomsen@gmail.com

Anders Malkomsen er lege i spesialisering i psykiatri ved Nydalen distriktspsykiatriske senter og stipendiat ved Seksjon for behandlingsforskning, Oslo universitetssykehus. Forfatteren har fylt ut ICMJE-skjemaet og oppgir ingen interessekonflikter.

\section{CARL TOLLEF SOLBERG}

Carl Tollef Solberg er ph.d., lege, filosof og seniorforsker ved Senter for medisinsk etikk, Institutt for helse og samfunn, Universitetet i Oslo.

Forfatteren har fylt ut ICMJE-skjemaet og oppgir ingen interessekonflikter.

Den norske debatten om psykisk helsevern avdekker stor avstand mellom forventninger og virkelighet. I somatikken godtar vi at sykdommer er kroniske og dødelige. Hvorfor gjelder ikke det i psykiatrien? 


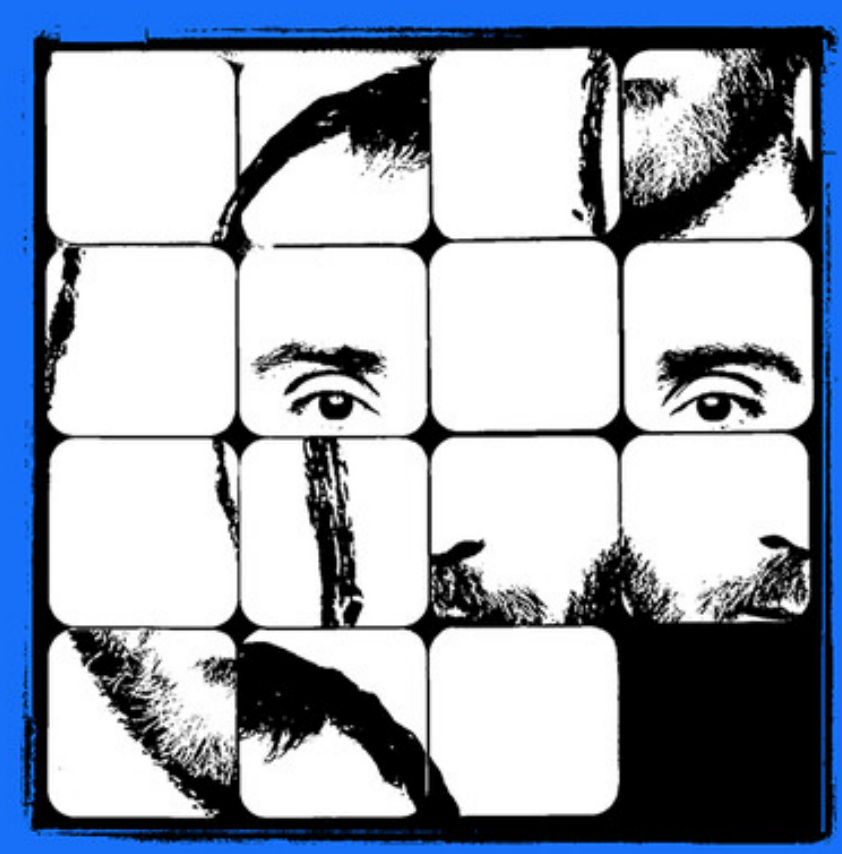

Illustrasjon: DmitriyKazitsyn og Morsa Images, via iStock. Kollasje av Tidsskriftet. Fortsatt blir mennesker psykotiske og tar liv. Slike hendelser omtales gjerne som «katastrofer» og som tegn på at psykiatrien har «mislyktes» (스). Fortsatt finnes det rusavhengige, og fortsatt dør noen av overdose etter endt behandling i institusjon. Da konkluderer avisene med at "systemet har svikta» (르). Fortsatt begår mennesker med psykiske lidelser suicid, og ikke sjelden blir medienes historie at «han kunne vært reddet» altså må det ha skjedd en feil (3). Sammen danner slike oppslag et tydelig budskap: Psykiatrien er i krise (4.).

Forsvarere hevder at psykiatrien er underfinansiert (5), og det tas til orde for at lovverket ikke åpner tilstrekkelig for å gi pasientene nødvendig tvangsbehandling (므). Ansatte i psykiatrien rapporterer om maktesløshet og en følelse av å ikke kunne gi pasientene den hjelpen de fortjener (7.). Vi tror mye kunne vært bedret dersom den offentlige samtalen fokuserte mer på det som ligger til grunn for mange av disse uenighetene: ulike forventninger til psykiatrien. Vår hypotese er at «krisen i psykiatrien» også er en forventningskrise - en opplevelse av krise som skyldes at urealistiske forventninger stadig ikke blir innfridd.

\section{Forventninger og nytte}

Det finnes evidens for at forventningene til psykisk helsevern er av betydning. Pasienter blir mer fornøyde når de får den behandlingen de forventer å få ( $\underline{8})$, hvilket understreker viktigheten av realistiske forventninger. En oversiktsstudie viser at de som forventer behandling av høy kvalitet, oppgir høyere grad av tilfredshet med tjenesten enn de som forventer behandling av lav kvalitet (ㅁ). Det er altså ikke et poeng i seg selv å senke forventningene til psykiatrien - det kan være en fordel at pasientene forventer god behandling.

\section{«Problemet oppstår idet forventningene blir urealistisk høye»}

Problemet oppstår idet forventningene blir urealistisk høye. Studier har nemlig vist at behandlingsresultatet påvirkes negativt av forventninger som ikke blir møtt, og at tiltak som justerer pasientenes forventninger, gir en bedre opplevelse av behandlingskvaliteten. 
Disse funnene gjelder også pasienter innlagt på psykiatriske institusjoner (9.).

Ofte er det slik at pasienter og leger har divergerende oppfatning av hva det innebærer å gi

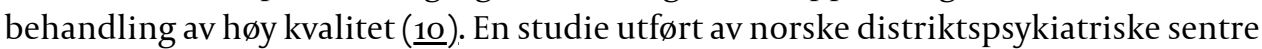
(DPS) viste at dette også gjelder norsk psykiatri (1ㅡ). Internasjonale studier tyder på at mange pasienter forventer at deres rolle kun består i å snakke med terapeuten, at terapeuten skal styre samtalene, at terapien skal gi en «quick fix» og at det ikke forventes at man gjør noe selv mellom terapitimene ( $(\underline{12})$.

"Selv optimal behandling kan ikke hjelpe alle, noe vi tror er bedre akseptert i somatikk enn i psykiatri»

Vår hypotese er at mange ansatte, pårørende og pasienter har urealistiske forventninger til hva psykisk helsevern kan gjøre for sine pasienter. Med urealistisk mener vi her alle forventninger som ikke er tro mot virkeligheten. Selv optimal behandling kan ikke hjelpe alle, noe vi tror er bedre akseptert i somatikk enn i psykiatri. For å illustrere dette vil vi kort sammenligne noen av forventningene til den psykiatriske og den somatiske spesialisthelsetjenesten.

\section{Hvor går grensen?}

I psykiatrien mangler det ofte velavgrensede endepunkter for behandling, spesielt i de mest alvorlige tilfellene. Hvor langvarig bør en terapi være, og når er pasienten frisk nok? Noen av behandlingsretningslinjene inkluderer forslag til varighet, for eksempel 1620 timer psykoterapi ved moderat til alvorlig depresjon, men for de fleste alvorlige tilstander blir anbefalingene vage og gir bud om «tilpasning» (13). Siden forventningene til den psykiske helsehjelpen som regel er omfattende og diffuse, og det forventes at nær sagt hele personens livsanskuelse skal behandles, ofte i overskuelig fremtid, oppstår det konflikter. Uklare forventninger og uklare føringer medfører gjerne medieoppslag der man fastslår at behandlingen ble avsluttet etter for kort tid (14).).

En forverring av kols behandles ved at den midlertidige forverringen stabiliseres, og behandlingen regnes som vellykket selv om pasienten skulle komme tilbake et par måneder senere med ny forverring. Dersom en psykiatrisk pasient behandles med samme intensitet og likevel får en forverring få måneder senere, vil den psykiatriske behandlingen raskt anses som mislykket. Slike tilfeller omtales ofte i mediene som psykiatriens "svingdørspasienter» (14,15). Denne type nedlatenhet brukes sjelden om somatikkens pasienter. Premisset for disse oppslagene er at det ikke er sykdommen som gir manglende bedring, men den mangelfulle behandlingen pasienten har fătt. Aksepten for at også psykiske lidelser kan være kroniske, synes lav.

I helsevesenet strekker vi oss langt for å forlenge liv og derigjennom utsette døden. Samtidig ser vi fantasier om nullvisjon for dødsfall i psykiatrien - og for psykiatriske selvmord i særdeleshet. Det har aldri vært et spørsmål om vi skal dø, men når og av hva. I Norge dør i overkant av 40 ooo mennesker hvert år. Hvorfor er det blitt et uttalt mål at samtlige av disse dødsfallene skal kunne tilskrives somatisk årsak? En nullvisjon for psykiatriske dødsfall er bare rasjonell dersom samtlige psykiatriske dødsfall de facto kunne vært unngått. Slik er det dessverre ikke.

\footnotetext{
«En nullvisjon for psykiatriske dødsfall er bare rasjonell dersom samtlige psykiatriske dødsfall de facto kunne vcert unngått. Slik er det dessverre ikke»
} 
Palliasjon har med tiden blitt en betydningsfull og viktig del av legeyrket, som formulert i den velkjente aforismen «sjelden kurere, ofte lindre, alltid trøste» (16 $)$. For psykiatrien er det derimot lite toleranse for at nok er nok. Psykiatrisk palliasjon finnes det heller ingen tilbud om. Sistnevnte ville nemlig krevd aksept for at også psykiske lidelser kan være intraktable og dødelige. I somatikken søker man å avslutte nytteløs behandling. Og avslutning av livsforlengende behandling med begrenset nytte og potensial for skade, kaller man behandlingsbegrensning (17.). Når man derimot avslutter nytteløs eller skadelig behandling i psykiatrien, blir det ofte slått opp i mediene med overskrifter av typen «får ikke flere sjanser» - som om psykiatrien ønsker å ta livet av sine pasienter (묘).

\section{Ulike forventninger}

Den som hevder at psykiatrien er i krise, bør først forsøke å flytte forventningene vedkommende har til psykiatrien over på somatikken. La oss spørre: Hvilke somatiske behandlingsformer er det som avkreves en nullvisjon for $\mathrm{død}$, ikke vedkjenner seg kroniske, uhelbredelige tilstander, motsetter seg palliasjon og behandlingsbegrensning samt har hele livsanskuelsen som endepunkt i overskuelig fremtid? Verken psykiatrien eller somatikken vil noen gang kunne klare å leve opp til psykiatriens krav om suksess. Ikke engang om hele oljefondet øremerkes til psykisk helsevern. Derfor bør vi heller begynne å stille realistiske krav til psykiatrien og våge å diskutere hva vi rimeligvis kan forvente.

Veien frem mot realistiske forventninger til psykiatrien er lang. For hvor kommer egentlig de urealistiske forventningene til psykiatrien fra? Vi gir ikke noe svar i denne kronikken. Trolig trengs det en mer åpen og ærlig samfunnsdebatt over lengre tid samt både historiske, sosiologiske og vitenskapsteoretiske blikk på psykiatriens egenart. Som en sped begynnelse tillater vi oss å fremme to konkrete forslag til mer realisme.

\section{«Verken psykiatrien eller somatikken vil noen gang kunne klare å leve opp til psykiatriens krav om suksess. Ikke engang om hele oljefondet øremerkes til psykisk helsevern»}

For det første: Nullvisjoner bør i hovedsak unngås. Særlig bør vi avvikle nullvisjonen for selvmord som ble foreslått av helseminister Bent Høie i 2020 (19). Per Fugelli tok et oppgjør

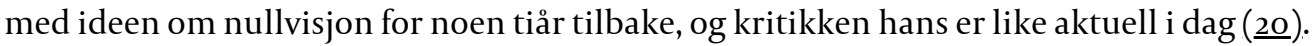
En nullvisjon innebærer at vi på samfunnsnivå har en moralsk forpliktelse til å unngå ethvert tilfelle av en gitt negativ hendelse. Hovedproblemet med en nullvisjon er at den ser bort fra kostnadene, både de økonomiske og moralske. Mengden av tvang og overbehandling som må til for å kunne innfri en nullvisjon om psykiatriske dødsfall, er trolig langt over det samfunnet egentlig ønsker.

Å godta at det finnes mennesker som blir så alvorlig psykisk syke at de dør av det, og at dette kan skje uten at psykiatrien har sviktet, er en klokere holdning til dette komplekse feltet. På samme måte som vi snakker om at pasienter «tapte kampen mot kreften», bør vi kunne si at noen pasienter rett og slett "tapte kampen mot depresjonen».Vi aner også konturene av nullvisjonstendenser for tvang i psykiatrien (1ㅡ). En forbilledlig motstemme mot dette ble fremmet i en kronikk som argumenterte for at vi må tåle noen av psykiatriens «ubehagelige sannheter» bedre enn vi gjør i dag( $\underline{\mathbf{2 2}})$.

For det andre: Psykiatrien bør engasjere seg i Legeforeningens kampanje Gjør kloke valg, der målet er at helsepersonell og pasienter sammen skal velge klokt innen diagnostikk og behandling (203). Norsk psykiatrisk forening er snart den eneste medisinske spesialistforeningen som ikke har foreslått tiltak for å redusere overbehandling innenfor eget spesialistfelt. Dette er neppe tilfeldig, men snarere symptomatisk for et spesiale som mangler en ordentlig intern forventningsavklaring. De fleste leger er nok fullt klar over de 
realitetene vi har beskrevet i denne kronikken. Likevel er det en vei å gå før psykiatrien klarer å bruke denne innsikten til å gjøre kloke valg. «Sjelden kurere, ofte lindre, alltid trøste» bør gjelde for hele medisinen.

\section{Realistiske forventninger}

Noen vil kanskje mistenke oss for å ha lave ambisjoner på psykiatriens vegne. Det er feil. Psykiatrien kan bidra til å løfte et menneske ut av en dyp depresjon og på den måten endre hele livsanskuelsen til vedkommende. Psykiatrien kan hjelpe et menneske ut av en psykose og på den måten bringe dette mennesket tilbake til virkeligheten. Sammenlignet med somatikkens behandlingsmål er dette nærmest for hybris å regne - og likevel lykkes man ofte. Vi tør hevde at behandling av alvorlige psykiske lidelser er noe av det viktigste og flotteste helsevesenet har å tilby.

Samtidig bør vi klare å ha to tanker i hodet samtidig, for realistiske forventninger er en forutsetning for optimalisert behandling. Og det er skjellig grunn til å mistenke at urealistiske forventninger til psykiatrisk behandling hos pasienter, pårørende og politikere gjør selve behandlingen dårligere enn den ellers kunne vært. Ett eksempel på dette er etableringen av såkalt medikamentfri behandling i psykiatrien. En norsk studie har vist at flertallet av pasienter på Jæren DPS ønsket seg et medikamentfritt behandlingstilbud. Forfatterne tolker disse funnene klokt når de skriver at dette kan «forstås som en frustrasjon over vedvarende symptomer, bivirkninger og stort lidelsestrykk på tross av medisinbruk» (24).

Ønsket om å slippe medisiner er nok ofte et uttrykk for urealistiske forventninger, et håp om å slippe sykdommen. Dessverre er det ikke alltid slik at om bare hjelpen hadde kommet tidligere, eller man hadde fått den behandleren eller behandlingsformen man ønsket, så ville alt gått bra. For også psykiatrisk sykdommer kan være inkurable og dødelige. Det må vi akseptere. Først da tar vi de psykiatriske pasientene på alvor.

Tusen takk til Julie Evensen, Jacob Jorem, Borgar Jølstad og Jan Ivar Røssberg for nyttige innspill.

\section{REFERENCES}

1. Haugan B, Ertesvåg F. Frp etter Kongsberg og Bislett:- En katastrofe. VG 14.11.2021.

https://www.vg.no/nyheter/innenriks/i/Kzb1XM/frp-etter-kongsberg-og-bislett-en-katastrofe Lest 12.1.2022.

2. Fjelldalen $\mathrm{H}$. Jannes mann døde av overdose - flere dør med legemidler som «oxy» enn heroin. NRK 26.9.2020. https://www.nrk.no/norge/jannes-mann-dode-av-overdose-_flere-dor-med-legemidlersom-_oxy_-enn-heroin-1.15171835 Lest 12.1.2022.

3. Hovland J, Moland A. Monika mistet sønnen i selvmord: - Han kunne vært reddet. NRK 28.8.2016. https://www.nrk.no/norge/monika-mistet-sonnen-i-selvmord_-_-han-kunne-vaert-reddet-1.13107998 Lest 12.1.2O22.

4. Helsepartiet. Nok festtaler: Psykiatri og psykisk helsevern er i krise! https://helsepartiet.no/wpcontent/uploads/2020/og/Psykiatrien-er-i-krise-Nok-festtaler-2020-LA.pdf Lest 12.1.2022.

5. Flor J. Bærebjelken i psykisk helsevern er råtten. Aftenposten 19.8.2020. https://www.aftenposten.no/meninger/kronikk/i/qLz1Ae/baerebjelken-i-psykisk-helsevern-er-raattenjoergen-flor Lest 12.1.2022.

6. Rasmussen K, Rosenqvist R, Melle KH. Vi vet hva som trengs i det psykiske helsevernet. https://www.aftenposten.no/meninger/kronikk/i/oGrdG2/vi-vet-hva-som-trengs-i-det-psykiskehelsevernet Lest 12.1.2022.

7. Dieset I. En vanlig dag på akuttpsykiatrisk avdeling. NRK 19.11.2021. https://www.nrk.no/ytring/envanlig-dag-pa-akuttpsykiatrisk-avdeling-1.15733821 Lest 12.1.2022.

8. Crow R, Gage H, Hampson S et al. The measurement of satisfaction with healthcare: implications for practice from a systematic review of the literature. Health Technol Assess 2002; 6:1-244. [PubMed] [CrossRef] 
9. Noble LM, Douglas BC, Newman SP. What do patients expect of psychiatric services? A systematic and critical review of empirical studies. Soc Sci Med 2001; 52: 985-98. [PubMed][CrossRef]

10. Shannon SE, Mitchell PH, Cain KC. Patients, nurses, and physicians have differing views of quality of critical care. J Nurs Scholarsh 2002; 34:173-9. [PubMed][CrossRef]

11. Bjørngaard JH, Ruud T, Garratt A et al. Patients' experiences and clinicians' ratings of the quality of outpatient teams in psychiatric care units in Norway. Psychiatr Serv 2007; 58: 1102-7. [PubMed] [CrossRef]

12. Armstrong S, Wammes M, Arcaro J et al. Expectations vs reality: The expectations and experiences of psychiatric treatment reported by young adults at a mood and anxiety outpatient mental health program. Early Interv Psychiatry 2019; 13: 633-8. [PubMed][CrossRef]

13. Helsedirektoratet. Nasjonale retningslinjer for diagnostisering og behandling av voksne med depresjon i primær- og

spesialisthelsetjenesten.https://www.helsebiblioteket.no/retningslinjer/psykisk-helse/depresjonnasjonale-retningslinjer-for-diagnostisering-og-behandling-av-voksne-med-depresjon-i-primaer-ogspesialisthelsetjenesten?lenkedetaljer=vis Lest 12.1.2022.

14. Pedersen TL. Gunhild er svingdørpasient. Bergens Tidende 23.9.2003. https://www.bt.no/nyheter/lokalt/i/AbzRA/gunhild-er-svingdoerpasient Lest 12.1.2022.

15. Eliassen H. Stortinget stanser nedbygging av psykiatrien. Tv2 Nyheter 15.2.2021. https://www.tv2.no/a/11951359/ Lest 12.1.2022.

16. Hem E. Tilbake til Hippokrates? Tidsskr Nor Lægeforen 2003; 123:3577-8. [PubMed]

17. Materstvedt LJ, Førde R. Fra aktiv og passiv dødshjelp til eutanasi og behandlingsbegrensning. Tidsskr Nor Legeforen 2011; 131: 2138-40. [PubMed][CrossRef]

18. Sandvig H. Caroline ønsker å leve, men får ikke flere sjanser i psykiatrien. NRK 17.12.2020. https://www.nrk.no/dokumentar/xl/caroline-fra-_helene-sjekker-inn_-far-ikke-flere-sjanser-ipsykiatrien-1.15259446 Lest 12.1.2022.

19. Regjeringen. Handlingsplan for forebygging av selvmord 2020-2025. https://www.regjeringen.no/contentassets/efgcc6bd2eo842bfgac722459503f44c/regjeringenshandlingsplan-for-forebygging-av-selvmord-2020-2025.pdf Lest 12.1.2022.

20. Fugelli P. o-visjonen - essays om helse og frihet. Oslo: Universitetsforlaget, 2003.

21. Tvangsbegrensningsloven NOU. 2019:14.

https://www.regjeringen.no/contentassets/78974ebb76oa412cb646611ad2e57b9d/no/pdfs/nou2019201 900140oodddpdfs.pdf Lest 12.1.2022.

22. Gardsjord ES. En ubehagelig sannhet. NRK 18.10.2021. https://www.nrk.no/ytring/en-ubehageligsannhet-1.15694010 Lest 12.1.2022.

23. Legeforeningen. Gjør kloke valg. https://www.legeforeningen.no/kloke-valg/til-helsepersonell/ Lest 12.1.2022.

24. Heskestad S, Kalhovde AM, Jakobsen ES et al. Medikamentfri psykiatrisk behandling - hva mener pasientene? Tidsskr Nor Legeforen 2019; 139. doi: 10.4045/tidsskr.18.o912. [PubMed][CrossRef]

Publisert: 9. februar 2022. Tidsskr Nor Legeforen. DOI: 10.4045/tidsskr.21.0895

Mottatt 15.12.2021, godkjent 12.1.2022.

(C) Tidsskrift for Den norske legeforening 2023. Lastet ned fra tidsskriftet.no 26. april 2023. 